\title{
Interstitial Hyperthermia in Combination with Radiation Brachytherapy for Treatment of Breast Tumor
}

\author{
OIENDRILA B DEBNATH ${ }^{1 *}$, KAZUYUKI SAITO², KOICHI ITO², \\ MITSURU UESAKA ${ }^{1,3}$

\begin{abstract}
${ }^{1}$ Department of Bioengineering, University of Tokyo, 7-3-1 Hongo, Bunkyo-ku, Tokyo 113-8654, Japan
${ }^{2}$ Center for Frontier Medical Engineering, Chiba University, 1-33 Yayoi-cho, Inage-ku, Chiba 263-8522, Japan

${ }^{3}$ Department of Nuclear Engineering and Management, University of Tokyo, 7-3-1 Hongo, Bunkyo-ku, Tokyo 113-8654, Japan
\end{abstract}

Abstract: Combination of interstitial hyperthermia and radiation brachytherapy has been shown to be effective for treatment of a tumor. After increasing the temperature, the tumor becomes sensitive to radiation dose, and as a result the radiation dose can be reduced.

The purpose of this study was to identify the appropriate invasive antenna array which can be effectively used on a deep-seated breast tumor to increase the temperature to more than $42.5^{\circ} \mathrm{C}$, and to examine the effect of a smaller cumulative radiation dose of $30 \mathrm{~Gy}$.

We have found coaxial-slot antenna array to be the most appropriate for applying hyperthermia on a deep-seated breast tumor. The temperature distributions were measured with a breast phantom, and specific absorption rate (SAR) distributions were calculated using a simulation software. A coaxial-slot antenna array, consisting of two coaxial-slot antennas, separated by $5 \mathrm{~mm}$, and using a microwave power of $15 \mathrm{~W}$ increased the temperature of a tumor phantom, in an area of $30 \mathrm{~mm}$ in diameter, to over $42.5^{\circ} \mathrm{C}$ in $30 \mathrm{~min}$. The temperature as well as SAR were observed to have increased more in the tumor tissue than in the other types of tissues which were tested. Thereafter, we have examined the radiation dose distribution of brachytherapy using a treatment planning software. Simulations were conducted on the Computed Tomography image of an anonymous breast tumor patient; the tumor's dimensions were $40 \mathrm{~mm}$ (length) $\times 30 \mathrm{~mm}$ (width). A radiation dose of 30 Gy given in 5 fractions of 6 Gy each, which is lesser than the conventional radiation doses used in external beam radiation therapy, was applied to the tumor. Harm to adjacent tissues is also expected to be minimized due to lower radiation dose.

As a result of this study, there is a possibility of local control of deep-seated small breast tumors using a combination of interstitial hyperthermia by using coaxial-slot antenna array to increase the temperature to over $42.5^{\circ} \mathrm{C}$ and radiation brachytherapy by applying cumulative dose of $30 \mathrm{~Gy}$.

Key Words: coaxial-slot antenna array, deep-seated breast tumor, interstitial hyperthermia, radiation brachytherapy, dose distribution

Received 24 March, 2017, Accepted 19 July, 2017: *Corresponding author: Tel, +81-3-5841-2917; Fax, +81-3-5841-2916;

e-mail, oiendrila.bhowmik@nuclear.jp

doi: 10.3191/thermalmed.33.53

o2017 Japanese Society for Thermal Medicine 


\section{Introduction}

Hyperthermia is an established form of cancer treatment therapy in which the temperature of a tumor is increased to over $42.5^{\circ} \mathrm{C}$ in an artificial way ${ }^{1-3)}$ by delivering heat using external sources, such as microwaves, ultrasound. Several studies have shown that high temperature causes direct damage to the cancerous cells ${ }^{2,4-10)}$ or sensitizes the cancerous cells to other treatment modalities ${ }^{10)}$ such as radiotherapy, chemotherapy, immunotherapy, with lesser injury to the normal tissues ${ }^{11)}$ than to the tumor tissues. Furthermore, over the past few decades various randomized clinical trials conducted on patients with different types of cancer have shown improved clinical response, local control and survival, due to combination of hyperthermia and radiotherapy ${ }^{1,3,11-16)}$.

Hyperthermia increases oxygen content-a strong radio-sensitizer-inside the cells. Tumor cells are more sensitive to temperature as compared to normal cells ${ }^{17,18)}$, thus the temperature can be increased in the tumor cells while maintaining a safe temperature in the normal cells. Moreover, radiation-resistant cells in the tumor can be destroyed by using combination of hyperthermia and radiation ${ }^{4)}$.

An additional advantage of using the combination of interstitial hyperthermia and brachytherapy is that the adverse effect on the other tissues adjacent to the breast tumor is minimized because the heat and radiation are focused on the breast tumor.

In the experiments, hyperthermia was applied using the frequency $2.45 \mathrm{GHz}$ as it comes under Industrial, Scientific, and Medical (ISM) band in Japan, the U.S., and some other countries.

\section{Methods}

\subsection{Hyperthermia: Description of the antenna array system}

Among the various antennas and antenna arrays tested, invasive coaxial-slot antenna array was observed to have produced the most desirable results for a deep-seated breast tumor. This paper describes the experiments and results of coaxial-slot antenna only.

In the experiments conducted, interstitial hyperthermia was applied on breast tumor phantoms. A coaxial-slot antenna was used to localize the heating effect. Advantage of using coaxial-slot antenna is the ability to heat deep seated tumors, with minimum diffraction.

Antenna parameters and the spacing between the slots for coaxial-slot antennas were calculated for the frequency of $2.45 \mathrm{GHz}$. The antenna was designed particularly for breast tumor. The coaxial-slot antenna is shown in Fig. 1. The parameters used for designing the antenna are listed in Table I. A coaxial-slot

Table I. Dimensions of coaxial-slot antenna

\begin{tabular}{|l|c|}
\hline \multicolumn{1}{|c|}{ Parameters } & Values \\
\hline Diameter of antenna & $1.19 \mathrm{~mm}$ \\
\hline External diameter of the catheter & $1.79 \mathrm{~mm}$ \\
\hline Thickness of the catheter & $0.30 \mathrm{~mm}$ \\
\hline Distance from the tip to the center of the slot close to the feeding point & $20.00 \mathrm{~mm}$ \\
\hline Distance from the tip to the center of the slot close to the tip & $10.00 \mathrm{~mm}$ \\
\hline Width of the slot & $1.00 \mathrm{~mm}$ \\
\hline Relative permittivity of the catheter & 2.6 \\
\hline
\end{tabular}

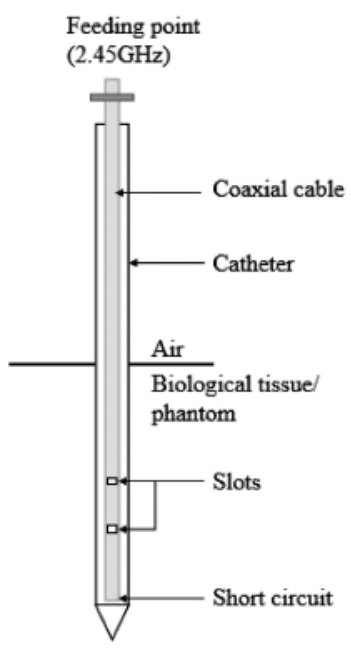

Fig. 1. Coaxial-slot antenna with two slots. 
antenna array was applied on different types of phantoms, having different dielectric values ${ }^{19)}$. The dielectric constants of the different types of phantoms are listed in Table II. The same values were also used for conducting the simulations.

Two coaxial-slot antennas, separated by $5 \mathrm{~mm}$, were used in the array in order to get the maximum

Table II. Dielectric constants of different tissue phantoms

\begin{tabular}{|l|c|c|}
\hline \multicolumn{1}{|c|}{ Parameters } & Relative permittivities & Conductivities (S/m) \\
\hline Skin & 72.9 & 0.49 \\
\hline Fat & 56.9 & 0.30 \\
\hline Muscle & 66.0 & 0.71 \\
\hline Fibro glandular & 68.8 & 0.79 \\
\hline Breast tumor & 79.2 & 0.80 \\
\hline
\end{tabular}
heating effect in the intermediate zone between the two antennas.

Similar experiments were conducted using other distances, such as $20 \mathrm{~mm}$, between the two coaxial-slot antennas. However, the heating effects were not found to be cumulative in those setups. Even for the noninvasive antenna arrays, maximum heating effect was observed when the distance between the edges of the antennas was $5 \mathrm{~mm}$.

\subsection{Hyperthermia: Calculation of specific absorption rate (SAR) and temperature}

The basic concept of SAR is that a tissue exposed to the electromagnetic radio waves absorbs power from these waves, and this power gets distributed throughout the tissue ${ }^{20)}$. The equation for SAR is shown in Equation (1).

$$
|\mathbf{S A R}|=\sigma \frac{|E|^{2}}{\rho}
$$

where $\sigma$ is the conductivity of the tissue $(\mathrm{S} / \mathrm{m}), \rho$ is the density of the tissue $\left(\mathrm{kg} / \mathrm{m}^{3}\right)$, and $|E|$ is the electric field $(\mathrm{V} / \mathrm{m})$.

The electromagnetic field around the antenna was calculated using the Finite Integration Technique $(\text { FIT })^{21)}$. The parameters for FIT calculations are listed in Table III. For FIT calculations a mesh structure of the antenna was created and boundary conditions were applied. The cross-sectional view of antenna and catheter, and boundary conditions are shown in Fig. 2. The length of antenna used was $140 \mathrm{~mm}$ and the depth of penetration of this antenna in the phantom was $70 \mathrm{~mm}$. The length of the boundary was considered to be $180 \mathrm{~mm}$.

The increase in temperature ${ }^{22,23)}$ due to application of the coaxialslot antenna was calculated using Penne's bio-heat transfer equation, shown in Equation (2). Body temperature was considered to be $37^{\circ} \mathrm{C}$.

Table III. Description of FIT parameters

\begin{tabular}{|l|c|c|}
\hline \multirow{2}{*}{ Description } & \multicolumn{2}{|c|}{ Values (mm) } \\
\cline { 2 - 3 } & Min & Max \\
\hline$\Delta x, \Delta y, \Delta z$ & 0.1 & 1.5 \\
\hline
\end{tabular}

$$
\left(\rho c_{p}\right)_{t} \frac{\partial T_{t}}{\partial t}=\nabla\left(k_{t} \nabla T_{t}\right)+q_{p}+q_{m}+\rho \mathrm{SAR}
$$

where $\rho, c_{p}, T_{t}, k_{t}, q_{p}, q_{m}$, and SAR are tissue density, tissue-specific heat, tissue temperature, tissue thermal conductivity, heat transfer from blood to tissue, uniform rate of metabolic heat generation in the tissue layer per unit volume, and Specific Absorption Rate respectively. For the calculations in this research work, tissue density $(\rho)$

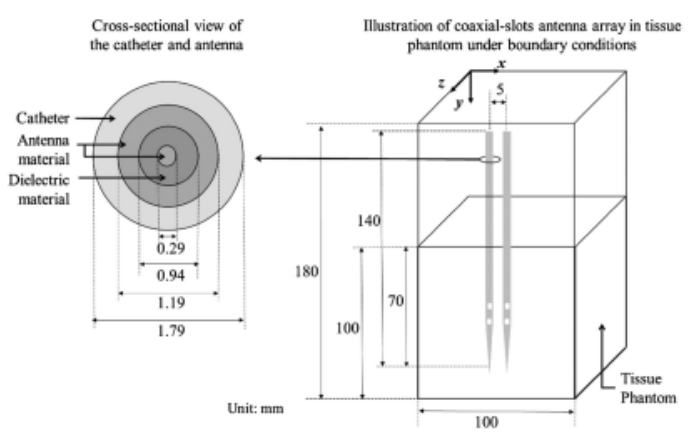

Fig. 2. Cross-sectional view of coaxial-slot antenna. 
was considered to be $916 \mathrm{~kg} / \mathrm{m}^{3}$, tissue specific heat $\left(c_{p}\right)$ to be $2,300 \mathrm{~J} / \mathrm{Kg} \cdot \mathrm{K}$, tissue temperature $\left(T_{t}\right)$ to be $37^{\circ} \mathrm{C}$, tissue thermal conductivity $\left(k_{t}\right)$ to be $0.33 \mathrm{~W} / \mathrm{m} \cdot \mathrm{K}$. From E. Saniei et al. ${ }^{24)}$, the rate of metabolic heat generation $\left(q_{m}\right)$ varies with the diameter of the tumor. Using the equations in the aforementioned paper, $q_{m}$ was calculated to be $4.7 \times 10^{3} \mathrm{Watt} / \mathrm{m}^{3}$ for a diameter of $10 \mathrm{~cm}$. The heat transfer from blood to tissue $\left(q_{p}\right)$ was disregarded - the temperature of blood and tissue were assumed to be the same in the experiments. The SAR varies; the value of SAR decreases when the distance from the catheters increases, as shown in the Fig 4.

The experiments were conducted using microwave power of $15 \mathrm{~W}$ and $20 \mathrm{~W}$.

Temperature at the surface of the phantom was calculated using Equation (3). This equation gives the heat lost from the surface of a phantom due to lower ambient temperature.

$$
\kappa \frac{\partial T}{\partial n}=-h\left(T-T_{a}\right)
$$

where $\kappa$ is the thermal conductivity, $\partial T$ is the change in temperature, $n$ is the unit vector normal to the surface of the phantom, $h$ is the convective heat transfer coefficient from the surface of the phantom to the outside air $\left(\mathrm{W} / \mathrm{m}^{2} \mathrm{~K}\right), T$ is the temperature, and $T_{a}$ is the ambient temperature $\left.{ }^{\circ} \mathrm{C}\right)$. In the experiments, $h$ was considered to be $10.5 \mathrm{~W} / \mathrm{m}^{2} \mathrm{~K}$ and $T_{a}$ to be $27^{\circ} \mathrm{C}$.

In the experiments, the temperatures were measured using a fiber optic temperature sensor inserted in the tumor phantom. Infrared images were also recorded using an infrared camera.

\subsection{Radiation Brachytherapy: Application method}

Normally brachytherapy is applied on a localized area by inserting a radioactive source in a catheter ${ }^{25}$. In this study, a method of introducing the radioisotopes in the same catheters as those that were used in hyperthermia is proposed. After application of hyperthermia, the coaxial-slot antennas will be removed whereas the catheters will be maintained in the same place. The radioactive sources will then be introduced in the same catheters as shown in Fig. 3. Iridium-192 is assumed to be the radioactive source.

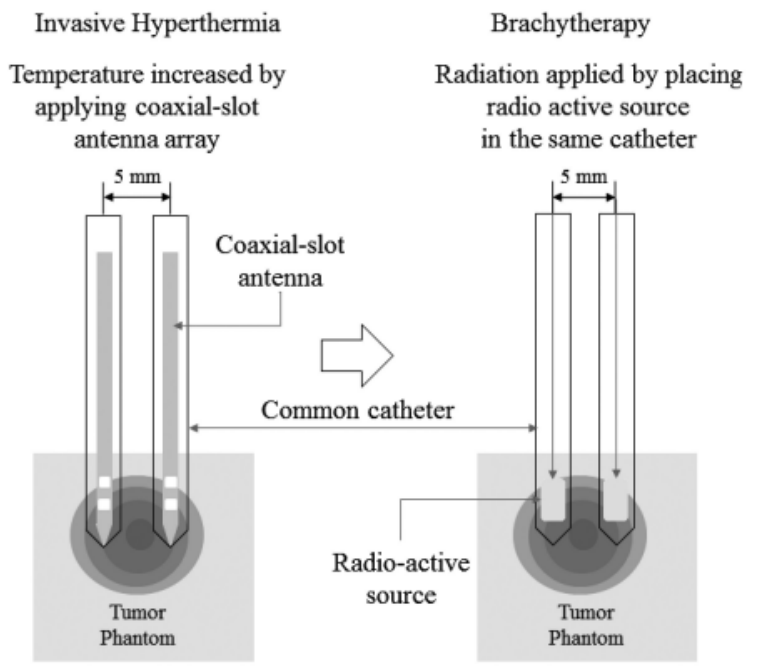

Fig. 3. Combination of two methods: hyperthermia and radiation dose distribution for breast tumor.

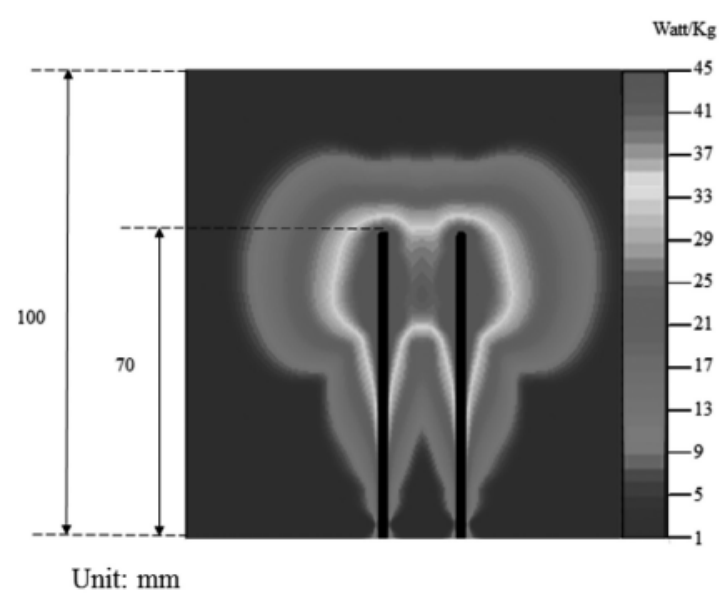

Fig. 4. SAR distribution of the coaxial-slot antenna array in tumor tissue phantom. 


\subsection{Radiation Brachytherapy: Calculation of the radiation dose}

A treatment planning simulation software based on the Monte Carlo method was used to observe the effect of radiation doses applied using brachytherapy. A CT image of an anonymous patient's breast tumor, which had dimensions of $40 \mathrm{~mm} \times 30 \mathrm{~mm}$, was used to conduct the simulations. Firstly, a Region of Interest (ROI) was drawn. Then a radiation treatment planning was conducted according to the spread of the tumor. In the experiments for hyperthermia, which were conducted using a coaxial-slot antenna array, the maximum increase in temperature was observed in an area of $30 \mathrm{~mm}$ around the catheters. In the simulations conducted for radiation brachytherapy, the same area of $30 \mathrm{~mm}$ around the catheters was targeted. The effect of radiation dose outside this target area was also observed.

\section{Results}

\subsection{Hyperthermia: Specific Absorption Rate (SAR) and temperature}

The SAR of a breast tumor tissue phantom is shown in Fig. 4. When the temperature of the tissue was increased to over $42.5^{\circ} \mathrm{C}$, the power absorption by the tissue generated this SAR pattern. The SAR was calculated for all the types of phantoms listed in Table II, and the breast tumor tissue phantom was found to have the maximum SAR distribution.

We observed that using the same experimental setup, a microwave power of $15 \mathrm{~W}$ increases the temperature of a breast tumor phantom to $45^{\circ} \mathrm{C}$ in $30 \mathrm{~min}$, whereas a microwave power of $20 \mathrm{~W}$ increases the temperature of a breast tumor phantom to $49^{\circ} \mathrm{C}$ in $30 \mathrm{~min}$.

Fig. 5(a) shows the experiment set up with the coaxial-slot antenna array applied on a phantom and Fig. 5(b) shows the infrared images after application of the antenna array. Due to different dielectric properties, the rate of increase in temperature is different for different types of tissue phantoms. The patterns of increase in temperature in different types of phantoms are shown in Fig. 6.

Using a coaxial-slot antenna array with a microwave power of $15 \mathrm{~W}$ on a tumor phantom of $30 \mathrm{~mm}$ in diameter, a temperature rise to $45^{\circ} \mathrm{C}$ was achieved in $30 \mathrm{~min}$. These experiments were

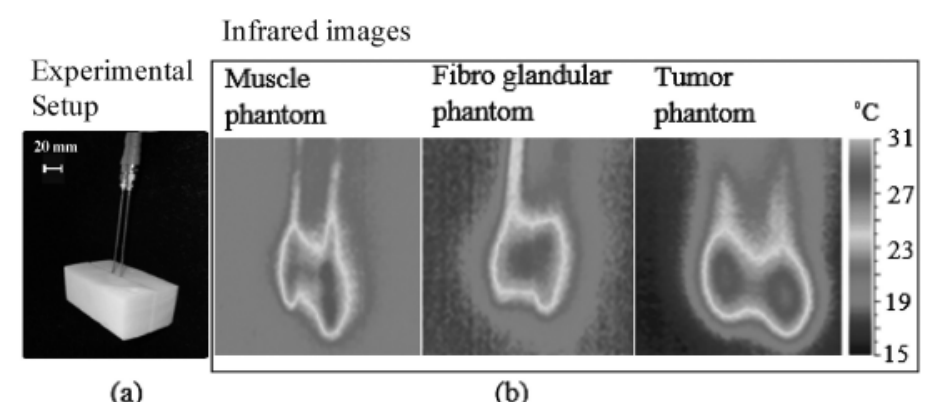

(a)

(b)

Fig. 5. (a) Coaxial-slot antenna array applied on a phantom; (b) Infrared images of different types of phantoms after applying coaxial-slot antenna array.

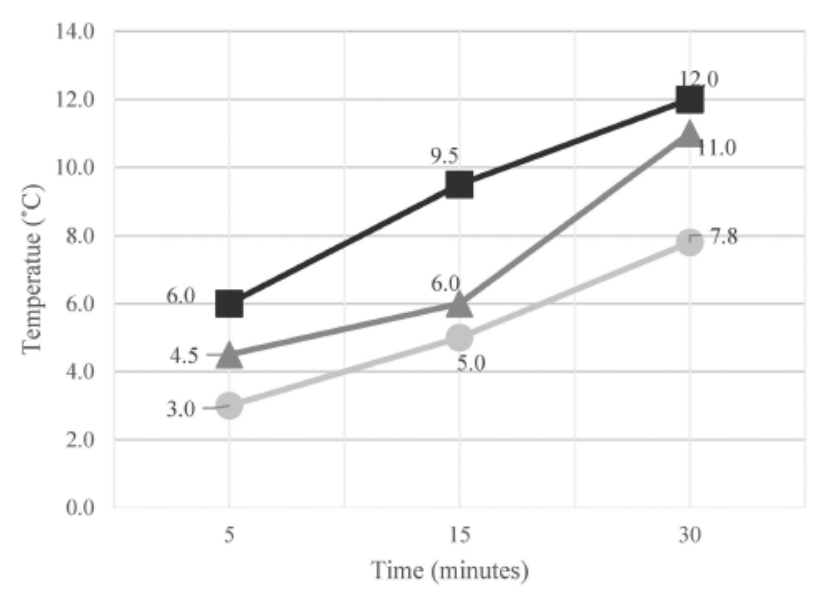

Fig. 6. Increase in temperature in different type of phantoms after application of coaxial-slot antenna. Circle symbols are used to show temperature increase in muscle; triangle symbols, temperature increase in fibro glandular; square symbols, temperature increase in tumor. 
conducted using homogenous phantoms. In practical scenarios, the increase in temperature is expected to vary due to the heterogeneous composition of a breast.

\subsection{Hyperthermia: Comparison of experiment and simulation results}

In both experiments and simulations, the dielectric constants of the phantoms were maintained the same as shown in Table II. However, there were differences between the results of practical experiments and those of simulations. The increase in temperature was calculated in simulation as well as in phantoms. Fig. 7 shows the difference between the temperatures achieved in experiments and simulations. With the same microwave power, the difference in temperature was found to be around $6^{\circ} \mathrm{C}$ to $9^{\circ} \mathrm{C}$. This difference is because of the different boundary conditions in experiments and simulations.

\subsection{Radiation Brachytherapy: Radiation dose}

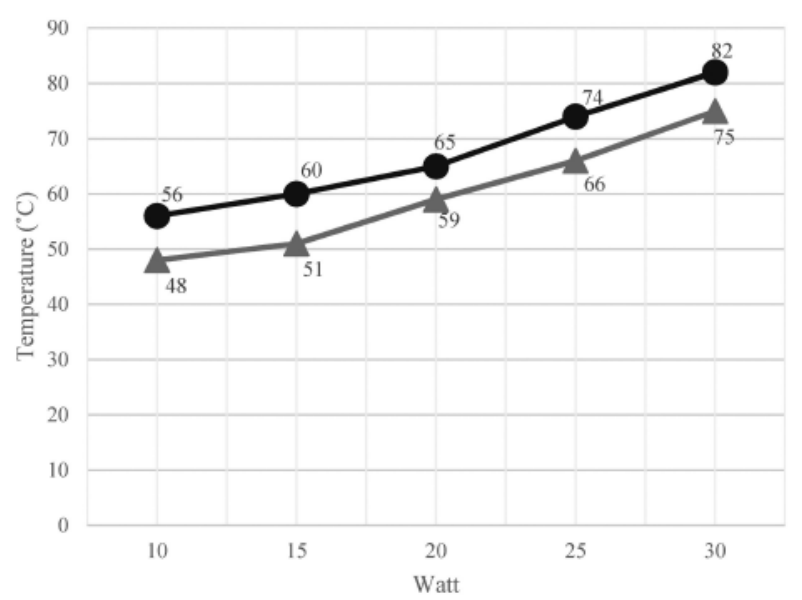

Fig. 7. Difference between the temperature rises obtained from experimental results and simulation results. Circle symbols are used to show temperature in simulation; triangle symbols, temperature in phantom.

In conventional external beam radiation therapy, generally a high cumulative radiation dose of $50 \mathrm{~Gy}$ to $60 \mathrm{~Gy}$ is applied ${ }^{26}$. There is a possibility that the radiation dose can be reduced if applied in combination with hyperthermia. Further investigations are required to accurately measure the reduction possible.

Fig. 8 illustrates the concept of applying brachytherapy in combination with hyperthermia on a breast tumor. The tumor is shown in black color. The maximum effect of the combination, an increase in temperature to over $42.5^{\circ} \mathrm{C}$ and a cumulative radiation dose of $30 \mathrm{~Gy}$, is shown using dark color. Lighter

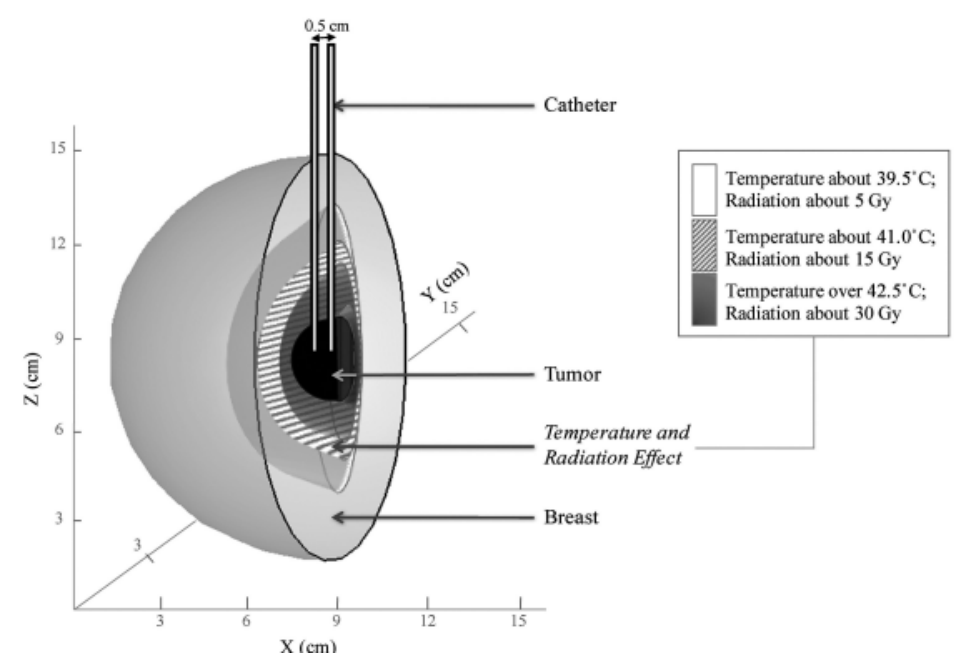

Fig. 8. Concept of combining temperature and radiation dose distribution. 
shades are used to illustrate that as the distance from the catheter increases, the effect of the combination decreases.

Fig. 9 shows the result of a simulation of radiation distribution after applying radiation sources using two catheters. The effects of various radiation doses were observed using simulations conducted for a breast tumor having the dimensions $40 \mathrm{~mm} \times 30 \mathrm{~mm}$. A cumulative radiation dose of $30 \mathrm{~Gy}$ was determined to be effective, with minimal harm to the adjacent tissues, for such a tumor.

Moreover, while in the immediate vicinity of the catheters, a cumulative radiation dose of $30 \mathrm{~Gy}$ was observed, as the distance from the catheter increased, the effect of radiation dose was reduced. In the region inside the inner circle colored in yellow — up to a distance of $30 \mathrm{~mm}$ from the catheter-a cumulative radiation dose of $30 \mathrm{~Gy}$ was observed; in the region between the inner circle colored in yellow and the outer circle colored in white-at a distance between $30 \mathrm{~mm}$ and $50 \mathrm{~mm}$ from the catheter-a cumulative radiation dose between $30 \mathrm{~Gy}$ and $10 \mathrm{~Gy}$ was observed; in the region over a distance of $50 \mathrm{~mm}$ from the catheter, a cumulative radiation dose of less than 10 Gy was observed.

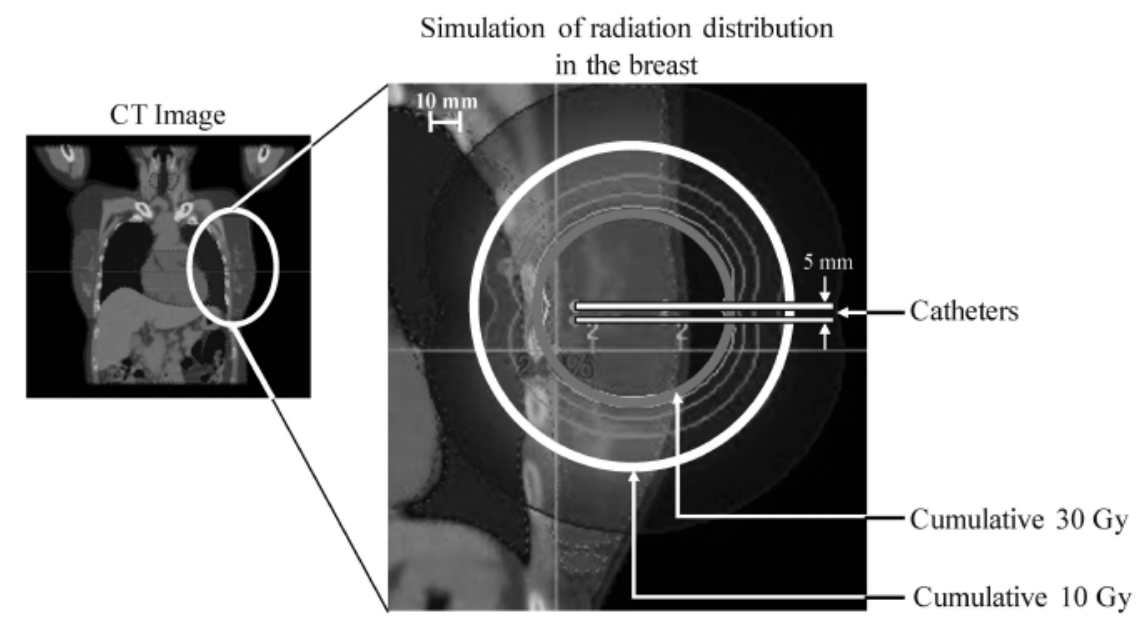

Fig. 9. Radiation distribution after applying radioactive source.

\section{Conclusion and future work}

Interstitial hyperthermia applied using a coaxial-slot antenna increases the temperature of the tumor tissues to over $42.5^{\circ} \mathrm{C}$ in $30 \mathrm{~min}$ of heating. A coaxial-slot antenna array was used in such a way that the temperature increase takes place in a localized area with minimal effect on the adjacent tissues. After increasing the temperature of the breast tumor to over $42.5^{\circ} \mathrm{C}$, a lower dose of radiation is expected to be effective for treatment.

In future, further investigations are required to accurately measure the possible reduction in radiation dose when applied in combination with hyperthermia.

\section{Discussion}

Several research studies as well as clinical trials have been conducted on the combination of hyperthermia and radiation dose distribution applied on different types of tumors.

Horsman et al. (2007) summarized the efficacy of the combination of hyperthermia and radiation dose 
distribution ${ }^{27,28)}$ based on an analysis of clinical trials conducted on 1,861 patients. These patients had tumors in various anatomical sites, such as the breast, head, neck, lugs, cervix, rectum, bladder etc., and due to the combination treatment, had displayed a significant improvement in the control of the tumors.

Although a phase III clinical trial conducted by Emami et al. (1996) had concluded that there are no beneficial effects of the combination of interstitial hyperthermia and radiation therapy as compared to radiation therapy alone, limitations in the quality of hyperthermia due to inadequacy of technologies available at that time, was mentioned to be a challenge ${ }^{29}$.

There is a strong case to further study, and to initiate a clinical trial, on the combination of interstitial hyperthermia and radiation brachytherapy on deep-seated breast tumors, using the proposed coaxial-slot antenna array which may compensate for the inadequacy of hyperthermia technologies which the researchers had access to in the past.

Two major categories of antenna are available in hyperthermia to heat the tumor: non-invasive and invasive. In the early phases of this research work, non-invasive antennas, namely, micro strip patch antenna and spiral antenna, were designed and tested on different types of phantom. The heating and depth of penetration were better in the case of spiral antenna as compared to micro-strip patch antenna. While both the non-invasive antennas gave good results for heating of a superficial tumor few centimeters beneath the skin, there was limited or no impact on deep-seated tumors. There was also a possibility of ablation of skin and other tissues adjacent to the tumor.

In conventional treatment of breast tumor, a combination of breast conserving surgery and external beam radiation therapy is used. A high radiation dose is given post-surgery and it covers a wider region. This method increases the impact on the normal tissues adjacent to the tumor.

Harry et al. (2007) had shown the results of a cumulative radiation dose of $50 \mathrm{~Gy}$ applied by external beam radiation therapy, with and without a radiation boost of $16 \mathrm{~Gy}$, on stage I and II breast cancer in 5,318 patients ${ }^{24)}$. The conclusion after a median follow up period of 10.8 years was that a boost of 16 Gy to the standard 50 Gy breast radiation therapy significantly lowers the risk of local recurrence rates.

In this research work, while the effect of a lower cumulative radiation dose of $30 \mathrm{~Gy}$ applied by brachytherapy was simulated using a CT image of an anonymous breast cancer patient, further investigations are needed to establish the effectiveness of this combination treatment.

Blood flow inside the breast is an important factor which impacts the temperature ${ }^{30}$. There may be some changes in the duration required to reach the desired temperature once blood flow is considered. While blood flow was not taken into account in the experiments conducted on the phantoms as part of this research work, it was considered in the simulations. As the blood flow is understood to significantly impact temperature, the effects of blood flow - both in the tumor and normal tissue - are recommended to be thoroughly considered in future studies.

At this point in time, despite a strong rationale for combining interstitial hyperthermia and radiation brachytherapy, interstitial hyperthermia is still an out of routine clinical practice. One of the reasons for hyperthermia's slow adoption is understood to be a need for high quality equipment, which in turn have to be operated by well-trained personnel. Based on the results from the studies hitherto and from this research work, we assert the need for further investigation on the effectiveness of combination therapy using interstitial hyperthermia and brachytherapy on deep-seated breast tumors. 


\section{References}

1) Chichel A., Skowronek J., Kanikowski M.: Thermal boost combined with interstitial brachytherapy in breast conserving therapy-Assessment of early toxicity. Rep Pract Oncol Radiother, 16: 87-94, 2011.

2) Marmor J.B., Pounds D., Postic T.B., Hahn G.M.: Treatment of superficial human neoplasms by local hyperthermia induced by ultrasound. Cancer, 43: 188-197, 1979.

3) Manning M.R., Cetas T.C., Miller R.C., Oleson J.R., Connor W.G., Gerner E.W.: Clinical hyperthermia: Results of a phase I trial employing hyperthermia alone or in combination with external beam or interstitial radiotherapy. Cancer, 49: 205-216, 1982.

4) Dewey W.C., Hopwood L.E., Sapareto S.A., Gerweck L.E.: Cellular responses of hyperthermia and radiation. Radiology, 123: 463-474, 1977.

5) Tsubouchi S., Kano E., Nishimoto Y., Nakamura W.: The effect of microwave-induced whole body hyperthermia on the mucosa of mouse small intestine. J Radiat Res, 25: 131-139, 1984.

6) Denman D.L., Elson H.R., Lewis G.C., Breneman J.C., Clausen C.L., Dine J., Aron B.S.: The distribution of power and heat produced by interstitial microwave antenna arrays: Comparative phantom and canine studies. Int J Radiat Oncol Biol Phys, 14: 127-137, 1988.

7) Terunuma H., Wada A., Deng X., Yasuma Y., Onishi T., Toki A., Abe H.: Mild hyperthermia modulates the relative frequency of lymphocyte cell subpopulations: an increase in a cytolytic NK cell subset and a decrease in a regulatory T cell subset. Thermal Med, 23: 41-47, 2007.

8) Terunuma H., Deng X., Toki A., Yoshimura A., Nishino N., Takano Y., Nieda M., Sasanuma J., Teranishi Y., Watanabe K.: Effects of hyperthermia on the host immune system from NK cell based science to clinical applications. Thermal Med, 28: $1-9,2012$.

9) Terunuma H., Deng X., Nishino N., Watanabe K.: NK call based autologous immune enhancement therapy (AIET) for cancer. J Stem Cells Regen Med, 9: 9-13, 2013.

10) Jones E.L., Oleson J.R., Prosnitz L.R., Samulski T.V., Vujaskovic Z., Yu D., Sanders L.L., Dewhirst M.W.: Randomized trial of hyperthermia and radiation for superficial tumors. J Clin Oncol, 23: 3079-3085, 2005.

11) Raymond U., Noell K.T., Woodward K.T., Worde B.T., Fishburn R.I., Miller L.S.: Microwave-induced local hyperthermia in combination with radiotherapy of human malignant tumors. Cancer, 45: 638-646, 1980.

12) Hornback N.B., Shupe R.E., Shidnia H., Joe B.T., Sayoc E., Marshall C.: Preliminary clinical results of combined $433 \mathrm{MHz}$ microwave therapy and radiation therapy on patients with advanced cancer. Cancer, 40: 2854-2863, 1977.

13) Kim J.H., Hahn E.W., Tokita N.: Combination hyperthermia and radiation therapy for cutaneous malignant melanoma. Cancer, 41: 2143-2148, 1978.

14) Xia T., Sun Q., Shi X., Fan N., Hiraoka M.: Relationship between thermal parameters and tumor response in hyperthermia combined with radiation therapy. Int J Clin Oncol, 6: 138-142, 2001.

15) Sakurai H., Hayakawa K., Mitsuhashi N., Tamaki Y., Nakayama Y., Kurosaki H., Nasu S., Ishikawa H., Saitoh J.I., Akimoto T., Niibe H.: Effect of hyperthermia combined with external radiation therapy in primary non-small cell lung cancer with direct bony invasion. Int J Hyperthermia, 18: 472-483, 2002.

16) Franckena M., Fatehi D., de Bruijne M., Canters R.A., van Norden Y., Mens J.W., van Rhoon G.C., van der Zee J.: Hyperthermia dose effect relationship in 420 patients with cervical cancer treated with combined radiotherapy and hyperthermia. Eur J Cancer, 45: 1969-1971, 2009.

17) Antich P., Tokita N., Kim J.H., Hahn N.: Selective heating cutaneous human tumors at 27.12 MHz. IEEE Trans Microw Theory Techn, 26: 569-572, 1978.

18) Baronzio G.F., Gramaglia A., Baronzio A., Freitas I.: Influence on Tumor microenvironment on thermoresponse: Biologic and clinical implications. Hyperthermia in Cancer Treatment: A Primer, Chapter 5, 67-91, 2006. 
19) Gabriel C.: Compilation of the dielectric properties of body tissues at RF and microwave frequencies. Report N.AL/OE-TR1996-0037, Occupational and environmental health directorate, Radiofrequency Radiaton Division, Brooks Air Force Base, 1996.

20) Saito K., Yoshimura H., Ito K., Aoyagi Y., Horita H.: Clinical trials of interstitial microwave hyperthermia by use of coaxialslot antenna with two slots. IEEE Trans Microw Theory Techn, 52: 1987-1991, 2004.

21) Marklein R.: Unified Numerical calculation of acoustic, electromagnetic, elastodynamic, and piezoelectric waves. Kleinheubacher Berichte, 43: 399-410, 2000.

22) Wang J., Fujiwara O.: FDTD computation of temperature rise in human head for portable telephones. IEEE Trans Microw Theory Techn, 47:1528-1534, 1999.

23) Pennes H.H.: Analysis of tissue and arterial blood temperatures in the resting human forearm. J Appl Physiol, 1: 93-122, 1948.

24) Saniei E., Setayeshi S., Esmaeil Akbari M., Navid M.: Parameter estimation of breast tumour using dynamic neural network from thermal pattern. J Adv Res, 7: 1045-1055, 2016.

25) Keisch M., Vicini F., Kuske R.R., Hebert M., White J., Quiet C., Arthur D., Scroggins T., Streeter O.: Initial clinical experience with the MammoSite breast brachytherapy applicator in women with early stage breast cancer treated with breast conserving therapy. Int J Radiat Biol Phys, 55: 289-293, 2003.

26) Bartelink H., Horiot J.C., Poortmans P.M., Struikmans H., Van den Bogaert W., Fourquet A., Jager J.J., Hoogenraad W.J., Oei S.B., Wárlám-Rodenhuis C.C., Pierart M., Collette L.: Impact of a higher radiation dose on local control and survival in breast conserving therapy of early breast cancer: 10 year results of the randomized boost versus no boost EORTC 2288110882 Trial. J Clin Oncol, 25: 3259-3263, 2007.

27) Horsman M.R., Overgaard J.: Hyperthermia: A potent enhancer of radiotherapy. Clin Oncol, 19: 418-426, 2007.

28) Horsman M.R., Overgaard J.: Overcoming tumor resistance resulting from hypoxia. "Basic Clinical Radiobiology for Radiation Oncologists, 3rd edition”. Ed G.G. Steel, Edward Arnold Publishers Ltd, pp.169-181, 2002.

29) Emami B., Scott C., Perez C.A., Asbell S., Swift P., Grigsby P., Montesano A., Rubin P., Curran W., Delrowe J., Arastu H., Fu K., Moros E.: Phase III study of interstitial thermoradiotherapy with interstitial radiotherapy alone in the treatment of recurrent or persistent human tumors: A prospectively controlled randomized study by the radiation therapy oncology group. Int J Radiat Oncol Biol Phys, 34: 1097-1104, 1996.

30) Strohbehn J.W.: Blood flow effects on the temperature distributions from an invasive microwave antenna array used in cancer therapy. IEEE Trans Biomed Engin, 29: 649-661, 1982. 